\title{
Guidelines for the Selection of Topical Content in ESL Programs
}

\section{Glenn Deckert}

The author contends that the topical content of ESL lesson materials in schools and universities is of ethical significance. Based on an established model for ethical judgment in social services, five guidelines for ethical selection of lesson topics are proposed and illustrated. Lesson topics must help ESL students: (a) adjust to local surroundings, (b) appreciate unfamiliar learning strategies, (c) explore genuine interests, (d) embrace institutional standards of conduct, and (e) foster mutual acceptance in the face of conflicting perspectives. After highlighting the benefits of applying these guidelines, the article calls for further refinement of this set of guidelines.

L'auteur affirme que le contenu thématique des leçons en ALS dans les écoles et les universités renferme une signification éthique. En s'appuyant sur un modèle éprouvé portant sur le jugement éthique dans les sciences sociales, il propose et explique cinq principes directeurs pour guider la sélection éthique de sujets de leçons. Les sujets des leçons doivent appuyer les élèves en ALS dans leur: (a) adaptation au contexte local, (b) appréciation des stratégies d'apprentissage inconnues, (c) exploration d'intérêts authentiques, $(d)$ adoption des normes institutionnelles $d u$ comportement et (e) considération positive de perspectives contradictoires. Après avoir fait valoir les avantages d'appliquer ces principes directeurs, l'auteur encourage la mise au point de cet ensemble.

In retrospect, I recalled that my one Middle Eastern student had tended to sit far to the side of the class and mostly keep his thoughts to himself. Only after he had missed three consecutive classes and I had been told he was seeking transfer to another section of this required ESL course did I realize that something had gone very wrong. To learn that he was too upset to talk with me personally was even more disturbing. Eventually, I learned from the program administrator and the department head the full measure of his resentment. What was the problem?

Piece by piece, the picture came together for me. In an earlier class my demonstration on how to give a two-minute news summary from minimal notes had marked me as his political adversary. In my sample presentation, I had unknowingly chosen what was for him an emotionally charged news report about a fatal Palestinian-Israeli shootout. That account came across to him as a piece of biased and slanderous reporting. Further, on another 
occasion, my reply to an Asian classmate's question on the meaning of "the evil eye," an expression from our reading passage, was perceived as ridicule of his own religious faith. So despite my own past years of residence in this student's region of the world, now in North America I had blundered and ignited flames of antagonism and reduced my class size by one. Although the testimony of an African Muslim classmate later seemed to exonerate me, I learned with much regret something about more judicious use of subject matter with my ESL students. Even more so now, after the events of September 11, 2001, and the ramifications of ensuing war on international terrorism, I should anticipate at least some students' sensitivity toward many topics I might bring to my ESL classroom.

My unfortunate experience with one student awakened me to my professional duty and ethical responsibility in both premeditated and spontaneous use of topical content in ESL classrooms. Over the past decades, we in the field of TESOL have gained a heightened sense of ethical responsibility on many fronts of the ESL/EFL enterprise. We have gained ethical perspective on representation of what an ESL program might deliver, the treatment of part-time ESL instructors, the making and use of tests, and the use and protection of human subjects in research. The issue of topical content in ESL lesson materials, however, is seldom viewed in terms of ethical responsibility. Johnson's (2003) recent discussion of values and moral decisions in a wide range of language teaching activities makes clear the need for thoughtful reflection on all aspects of ESL endeavor. Certainly the topical content of lesson material is one of those aspects. Textbook authors and publishers, in some sense, have demonstrated a measure of ethical awareness in ESL textbook content. They have rid publications of much ethnocentrism and stereotypical imagery. More self-criticism on content may be needed. For example, Heiman (1994) has questioned the appropriateness of assuming Western materialistic values in ESL textbooks. Speaking to instructors themselves, Silva (1997) has called for ethical sensitivity in determining the topics of writing assignments. He cautions against imposing Western themes to the neglect of topics the students prefer to explore. Nevertheless, a broader statement of professional and ethical standards in the selection and use of topics in ESL teaching materials has not yet emerged.

\section{The Purpose of This Discussion}

In the light of the need for ethical awareness in determining topical content for ESL courses, I first examine the growing need for guidance in this area and then present one legitimate model for conceptualizing ethical guidance. Then, drawing on the model, I propose five guidelines for the selection of topical content for ESL learners who enter North American classrooms from a wide range of diverse sociocultural and educational backgrounds. The explication of these guidelines is accompanied by specific examples of their 
application. Finally, I suggest sources of input for further understanding on responsible determination of topical content used for mediating language lessons in schools and universities.

\section{A Timely Source of Guidance}

Ethical awareness in the selection of ESL topical material is particularly relevant in that ESL instructors now commonly use authentic materials of their own choosing to supplement or even constitute the larger portion of teaching materials. That is, following the tenets of the communicative approach in their teaching, instructors are less inclined to adhere to predetermined linguistic syllabi, mere notional-functional categories, or set topical outlines in their routine teaching. This holds true in both courses that focus on oral skills and those that emphasize reading and writing. The instructor's freedom in introducing his or her own materials, it can be assumed, increases with the rising level of student proficiency. At all times, the instructor's aim is to select high-interest topics and create related tasks that wholly engage and challenge the learners at their level of language proficiency. Thus topical content in ESL courses has become an increasingly manipulable variable in the hands of the instructor. Subject matter is constrained only by students' proficiency level, their cognitive maturity, practical accessibility to the desired materials, and the consent of both students and instructor.

As instructors increasingly exercise freedom to select and incorporate their own materials into the course curriculum, there is sound rationale for their adopting authentic materials, that is, materials that have emerged as real-life messages in society, and not with any intention of teaching a target language. They are viewed as authentic both in their making and in their communicative purpose. These materials are, in substance, exactly what ESL learners encounter once they step outside the language classroom and try to make their way in the surrounding society. Nunan (1988) includes in his sample of authentic materials "video clips, recordings of authentic interactions, extracts from television, radio and newspapers, signs, maps and charts, photographs and pictures, time tables and schedules" (pp. 99-100). Certainly, downloaded Web site material can be added to the list. Although Dunkel (1995) recognized a trend among ESL material writers to incorporate authentic materials into commercial ESL textbooks, there is a daily influx of usable new, authentic materials for instructors to consider in making their selections. Some may feel compelled to edit or gloss these materials, especially when they are to be used with beginner or low-intermediate learners, but the contents and basic structures remain intact. The sheer vastness of these available materials calls not only for pedagogical awareness, but, in light of the topics they embody, sensitivity and ethical discernment as well.

One viable source for establishing the ethicality of topical content is found in Kitchener's (1984) ethical model composed of five ethical principles. She 
maintains that these principles, with some variation, are widely recognized in a range of service professions. Although they are clearly embedded in Judaic-Christian teaching, she recognizes parallel teachings in the tenets of Buddhism, Hinduism, and early Greek thinkers. Drawing on the explication of these principles in the field of biomedicine, Kitchener $(1984,2000)$ applies them to practitioners in the field of psychology, and Welfel (1990) applies the same in the field of student services. The five principles enable practitioners, and here ESL professionals, to assess the ethical dimension in services or situations when established codes prove insufficient. Kitchener's (1984) principles are summarized as follows.

- Autonomy. A course of action must respect and encourage persons' free choice and self-rule to the extent that there is no infringement of the rights of others. This applies even when the practitioner sees the other's free choices as ill advised.

- Nonmaleficence. A course of action must avoid causing intentional harm or discomfort to others. It must not violate another's well-being or interests.

- Beneficence. A course of action must foster the health, well-being, and interests of others. At the same time, mindfulness of the accompanying principle of autonomy minimizes the risk of paternalism in the pursuit of beneficence, that is, in seeking the good of others.

- Justice. A course of action must distribute resources and apply standards to all persons equally. The assumption is that all persons are equal and are to be treated as such unless there is some relevant unequal characteristic justifying unequal treatment. Ethical theorists have identified justice in the broad sense with fairness.

- Fidelity. A course of action must represent adherence to mutual agreements, promises, and truthfulness. It refers to faithfulness and honesty, qualities that undergird satisfying human relationships.

Kitchener (1984) maintains that the ethical principles are grounded in more abstract ethical theory. She recognizes that other principles exist and adds that these principles are not absolute. Two principles may be in tension with each other in a given situation, requiring one to give way to the other in seeking the greater good for all relevant parties. Yet all five commonly contribute to the determination of ethical conduct or resolution. Here, I maintain, they are highly relevant to the ethical determination and use of appropriate topics in ESL lesson material. The proposed five principles are to be kept in view when preparing ESL lessons, sometimes in the face of challenges from existing textbooks, unenlightened administrative practices, contrary student inclinations, and the personal biases of instructors. 


\section{Applying the Standards to ESL Lesson Content}

With the above ethical principles in view, I have formulated five guidelines for evaluating topics that instructors and publishers may adopt for their ESL lesson material. These five do not correlate with the five ethical principles in a one-to-one fashion. Rather, each guideline attains ethical significance by virtue of its relevance to one or more of the stated ethical principles. The guidelines have in view the ESL students' safe passage through the experiences of culture shock toward satisfying adaptation into a new community, whether it be a public school or an institution of higher education. The implementation of each guideline is illustrated, sometimes by reference to specific available material, to show the practical application of a given guideline and the ethical principles it represents. The first three guidelines to follow are about facilitating ESL students' adjustment to their school or new learning environment, whereas the last two aim to help students themselves adopt appropriate behavior and professional standards.

Materials should include topics that further students' adjustment to the local community. This is especially necessary for ESL students in secondary or higher education classes who have just arrived from another country. Young adults new to a Western English-speaking setting inevitably encounter some degree of culture shock and need for adjustment. Although many of the immediate survival needs of these students are routinely addressed by special offices of each institution, it is the ESL instructor who is best positioned to detect continuing needs for cultural adjustment. It would hardly be expected that these needs be as apparent to the instructor of a large physics or economics class, especially when the class is composed primarily of native speakers in which mainstreamed second-language users often retreat to silent observation. The ESL instructor, on the other hand, by virtue of a usually smaller class and probably a keen familiarity with the needs of immigrants or international students is more able to incorporate relevant topics that address issues of social adjustment without sacrificing course aims. In addition to practical matters such as shopping, housing, and health care, discussion can address safe avenues of contact and friendship with native speakers of English both in and outside the educational setting. Just the topic of communicative gestures can spare students blundering and embarrassment. For example, intermediate level learners, especially adults concerned about employment, could read and discuss excerpts from a text like Kiss, Bow or Shake Hands: How to do Business in 60 Countries (Morrison, Conaway, \& Borden, 1994).

Duff's (2001) ethnographic study of ESL students' roles in Canadian secondary schools points to a need for including in the curriculum sources of popular culture to facilitate learners' exchanges with native speakers. She concludes from her study that students, 
besides needing literacy skills to read the front pages of newspapers or academic texts and the listening comprehension to extract highlights from radio, television, and teachers' accounts of the news, students needed a more general pop-culture literacy, contained in mass media such as magazines (e.g., for girls, Teen, People, Seventeen; and for boys, magazines about cars, sports, or music), certain youth-oriented radio stations and other media. (p. 117)

As ESL students digest something of the themes, personalities, symbols, and idiom of these popular materials, they become more prepared to gain entrance into the mainstream society of their native speaking peers. This, in turn, gives them grounds for confidence to participate in "highly intertextual or hybrid oral texts" (Duff, 2002, p. 486) of their peers, both outside the ESL classroom and eventually in the classrooms where they need to assume roles with native speakers of English.

ESL students, especially in Canada, can find encouragement and exposure to the popular idiom from columnist Varadi (2004) whose Toronto Star column has addressed them directly: "Find people to practice your English with, watch TV, watch movies, listen to music and sing along" (p. 3). Her readable text further includes testimonies of minority students like that of 12-year-old Michelle:

I'm from Trinidad. I speak a different type of English called Creole. It was bad because I came from hot sun and into the opposite. I came around November and it was cold. After I came in the school, the children never really spoke to me and made fun of me because I speak different. Some weeks after, people began talking to me so I felt better. It gets better but it takes time. (p. 3)

In introducing students to the communicative customs of the local culture, the instructor upholds the ethical principle of beneficence in promoting students' facility and well-being in social relations outside the classroom and eventually for classroom participation with native speakers. Silence on such matters would be tantamount to violating the principle of nonmaleficence as learners are left to learn through awkward exchanges and sometimes costly blunders. In effect, the guideline fosters the learners' autonomy, that is, equipping them for expanded self-rule.

Materials should facilitate students' adjustment to classroom methodology. A large number of ESL students have previously studied English, primarily in teacher-centered, form-focused classes that emphasize mastery of discrete grammar points and vocabulary items divorced from meaningful communication. This previous educational experience constitutes what Cortazzi and Jin (1999) term students' culture of learning, that is, their notions of "what kinds of interaction are appropriate in class" (p. 196). Accordingly, some enter their new language learning context supposing that language instruc- 
tion is nothing other than teacher-centered instruction. Consequently, the ESL instructor using a communicative approach must help students understand the rationale behind using this approach and the benefits to them of doing so. If, in fact, the communicative approach is more promising, it is incumbent on the instructor to help learners see that the different classroom atmosphere is not a matter of an instructor's relaxed style or disinterest in language accuracy, but a sound strategy for developing communicative skill in English.

This different understanding of how a second language is most readily acquired can be mediated orally to the students by the instructor or presented to more advanced students through carefully selected journal articles about teaching techniques and ways of learning. Students' own journal entries on their ongoing language learning experiences, with their consent, can make for interesting class-wide reading and discussion. For example, one of my Chinese learners once concluded a journal entry on her experience in reading comprehension as follows.

I can describe a book clearly in Chinese, but I cannot do that in English. I seem to have two brains: Chinese and English. In "Chinese brain" I have a lot of thoughts, ideas, and words. In "English brain" I have nothing but words.

Class reaction to such an excerpt from a classmate can open new understanding of struggles, styles, and strategies of learning. Another source of material for helping students adjust to the communicative approach to learning is Brown's (2002) volume Strategies for Success: A Practical Guide to Learning English, a text featuring "strategy-based instruction." This supplementary textbook, designed for intermediate level students, aims to help students discover their own preferred way of learning. Further, extracts from professional newsletters or journals can be paraphrased or circulated for reading to help students understand current methodology and learner strategies to gain the most from their classroom experience.

The communicative approach to teaching that majors on students speaking up in class readily clashes with many students' ingrained classroom habit of mere attentive listening. Thus the ESL instructor must not only ease students into a new classroom role, but realize something of the inner struggle that this entails for the students. Watson (1999) among ESL students in Australia reports why they often hesitated to speak up in class. For example, inquiry found that students fear that classmates would consider their questioning a waste of class time. In Canada, Duff (2002) observed that mainstreamed students were uncomfortable asking for explanations in class because doing so put them at risk of ridicule and made them appear different from others. In response to these and other student perceptions, a class can 
engage in its own brainstorming on reasons for non-participation and ways of overcoming the hesitations.

While guiding students into new ways of learning, instructors must not assume that the communicative approach necessitates the dismissal of students' own past ways of learning. Many ESL students have demonstrated remarkably high levels of English proficiency acquired in large measure through traditional drill and memorization in their home country EFL settings. Students can be encouraged to continue using techniques and strategies they themselves have found helpful while gradually gaining confidence in new ways of learning, now in an English-speaking environment. In terms of Kitchener's (1984) ethical framework, this is investment toward the learner's autonomy or self-rule in learning. This emphasis also furthers the learner's well-being upholding the principle of beneficence and simultaneously honoring the principle of fidelity as the institution delivers the services and facilitates the learning for which the student has enrolled.

Materials should feature topics that relate to students' shared interests. Most students in ESL classes, especially in tuition-based higher education, are highly purpose-driven. In most language programs beyond those based in public schools, ESL learners pay tuition for instruction even though some would prefer to bypass this in favor of so-called content classes for academic credit. Accordingly, ESL administrators and instructors must keep in view the students' foremost academic or practical interests in learning. It is now well established that learners are able to gain knowledge of the world and many academic subjects through the avenue of ESL content instruction. Providing language instruction through topics of shared interest is comparatively easy for homogeneous classes. For this, there exists a growing supply of ESL textbooks with a content-based orientation for high school subjects, occupational needs, or various university-level disciplines. In actual fact, however, most ESL classes, especially in higher education, consist of students who represent a wide range of disciplinary interests. Thus following topics related to students' personal and pedagogical adjustment, topics of material should be chosen as much as possible to satisfy the prevailing common interests of the class. Were one to select topics that concentrate on the disciplinary interests of some students in a class while ignoring those of others, one would be overlooking the principle of justice or fairness.

Conducting a systematic survey of interests among cohorts of students enables an instructor or program director to discover common interests that are only marginally related to any disciplinary track. My own survey of 170 ESL students in a university ESL program illustrates students' preferences. Enrolled ESL students were asked to choose up to 10 topics from a list of 20 to indicate those they would find most satisfying for class discussion. For the sample as a whole, the most preferred topics were: (a) equal opportunity for women in education and employment, (b) the power of commercial advertis- 
ing, and (c) marriage and family customs. Differentiation by sex became apparent. Among the 102 female respondents in the sample, the same three topics prevailed, but among the 68 males, the top three choices were (a) the power of commercial advertising, (b) the increase of violence in American cities, and (c) the use of drugs among young people. Certainly texts can be found on the Web for class readings or teacher-guided discussion on all these topics. In respect to the widely shared interest in opportunities for women, feature articles in newspapers on employment trends in North America and elsewhere have been well received as lesson material by the surveyed students and their successors when materials matched the proficiency levels.

Whether by means of an instructor's formal research over time or through immediate class discussion to determine majority opinion, students themselves welcome having a major role in selecting the topics of materials to be used. In respect to the five ethical principles adopted by Kitchener (1984), this attention to shared subject interests of participating students fulfills the principle of beneficence as well as that of fairness.

Materials should address the ethical expectations of an academic community. It is at this point that the proposed guidelines implicate the ethical obligations of not only the instructors, but the ESL students themselves. Although many areas of ethical expectation in the university community may be encountered in handbooks and orientation sessions, it is in an ESL classroom that students may have their first responsibility to demonstrate these standards consciously. Here they must learn prevailing Western notions such as of plagiarism, copyright, discriminatory expression, and personal privacy. These may be presented by means of both printed materials and teacher modeling. A further quality of professionalism, if not ethical obligation, is collegiality, or willingness to assist others in the pursuit of knowledge and skill. For the ESL student, time spent in group work offering other students ideas toward improving content or structure in their essays may be a first step in learning to invest in the success of classmates.

At the same time, instructors can hardly represent the school or university community as a consistent model of exemplary professional demeanor. Thus students must not only get acquainted with the standards, but realize that unfortunate exceptions to the ideal do exist. Russy (2003), trustee member of a major university and former professor, points out the unhappy truth of reported ethical disregard in the academic community. Referring to faculty members, she recognizes the fact of

lateness for class, use of vulgarity in scholarly forums, showing favoritism among students, improper use of campus funds, plagiarism, sexual liaisons with students, failure to perform administrative duties, and most basic, unwillingness to uphold the value of truth in teaching and research. (p. B20) 
Consequently, students need to gain clarity not only on the nature of the standards, but also on the capacity to distinguish between acceptable and unacceptable patterns of behavior among those who are expected to model the standards. These standards and attitudes are all of critical importance on every level in the functioning of a genuine academic community. Violation of the standards weakens the academic community, and all members of the community, including the ESL students, must understand this. For most ESL students, the ESL classroom is their learning laboratory for observing and working toward attaining the ethical standards. Here the instructor can help to instill the standards through example, selected readings, and open discussion.

Of all the standards to be instilled or underscored in the minds of ESL students, the avoidance of plagiarism is often the most immediate and problematic, especially in classes that require extensive writing. Indeed, reports of the spread of plagiarism and the ease of accessibility to term paper mills in universities at large are undeniable. Schmidt (2004), writing for the National Post (Canada), reports a Canadian national survey that found "one in three undergraduate students admitted to committing plagiarism at least once in their academic careers" (p. A20). ESL students, however, frequently produce texts that feature a special shortcoming often questionably identified as plagiarism. When an instructor simply has students summarize a text, he or she is sure to find strings of unaltered language reappearing in the students' supposed summaries. The English learners who copy strings of text as their own in this manner are usually simply respecting the original writer's superior command of English, conceding their own linguistic limitations and not wanting to misrepresent the original writer's thought. Many are also displaying a writing habit that was largely accepted in their past EFL schooling. Thus the ESL class must not only learn the essential conventions of form in writing, but how to avoid unacceptable copying from sources and the charge of plagiarism. One helpful site among many on the World Wide Web is entitled Avoiding Plagiarism. Provided by the Sir Wilfrid Laurier Secondary School in Ontario, Canada, it offers students practice in recognizing acceptable and unacceptable renderings of a sample text (www.swil. ocdsb.edu.on.ca/ swl_library/plagiarism.html). Similar Web site material or clippings from either campus or community newspapers may lead to classroom discussion on plagiarism and other professional standards or required school behaviors.

Expectations beyond the avoidance of plagiarism are many. Ethical issues in student-instructor relations are addressed in a readable article by Messerschmitt, Hafernik, and Vandrick (1997) who point out institutional constraints on students' giving gifts and favors to instructors. The meaning of confidentiality, norms of politeness, and expectations of punctuality may be presented by way of print, graphics, or discussion. Although ESL instructors 
have no more claim on these standards than do other instructors in an educational community, ESL instructors are most able to ensure students' understanding and compliance, and their selection of relevant topical material is a major means of accomplishing this.

It is true that some students enter ESL programs with a mature understanding of many or even all these standards. Others, however, come with years of contrary educational experience in some of these areas. Thus ESL instructors are duty-bound to help students understand their own incumbent ethical responsibilities in an academic community and to know that those who disregard these, be they plagiarizers, opportunists, or chauvinists, need caring intervention. The aim is to see that all students who pass through the ESL classes grasp the nature and significance of ethical conduct and the principles on which they rest. In terms of Kitchener (1984), equipping students themselves to practice ethical behavior in the educational institution and beyond honors both the principles of justice and fidelity.

Materials should promote mutual respect toward the world and life views of others. The last of these five guidelines is an extension of the previous one, an ethical obligation toward other members of one's school or academic community. Should manageable reading materials to promote this understanding be hard to find, modeling and open discussion are alternative means of presentation. This guideline rests on the fact that in an ESL class, especially when composed of young or older adults, there are probably sharp differences in outlook on the world and in conceptions of the highest good. Although the entertainment industries, along with instant electronic communication, seem to be drawing persons of diverse cultures closer together, ESL students, nevertheless, represent a variety of conscious or latent belief systems. Students who have been reared and schooled in a culture anchored in the traditions and literature of, for example, Confucianism, Hinduism, or Islam, have distinct patterns of outlook on many issues. These can be in noticeable tension with the prevailing assumptions of pluralistic Western societies, as well as in tension with views of other language learners. Some students, in fact, come from societies that do not acknowledge freedom of choice on matters of religious faith or political perspective as heralded by the United Nations Universal Declaration of Human Rights. Thus students may bring to ESL classrooms differing orientations on the phenomena of gender roles, conflict resolution, freedom of speech, forms of acceptable entertainment, and public expression of affection. At a deeper level, there are differences in views of the sacred, of non-negotiable absolutes, and of the way to favor with the Ultimate. Western instructors and their ESL students can find themselves far apart on many of these value judgments, without even mention of the radically different foreign policy stances of their respective countries.

Heiman (1994) reminds us of the possibility of values that are sometimes simply assumed in ESL or EFL textbooks that may conflict with the world 
and life view of learners. Commenting on the values inherent in published materials of a decade ago and more, she wrote,

EFL texts continue to present images and contexts in which material wealth, economic growth, and personal acquisition are portrayed as a norm.... Empirical science is portrayed as the means of understanding the nature of life; evolutionary theory is largely presented as fact. (pp. 5-6)

Even now, ESL instructors can be quite innocent of the disparity between the portrayed values of textbooks and that of their learners. On the other hand, some language instructors in the face of the disparity between their own values and those of their students have chosen to bring value change tactics to the classroom. Their justification is critical pedagogy as championed by Freire (1970) and more recently by Pennycook (1994). Such was the challenge given by one plenary speaker at the March 1996 TESOL conference in Chicago in a talk entitled "The Art of Subversive Teaching." The speaker urged the audience to generate in-class discussion about gender imbalance and passive acceptance of authoritarian rule in students' EFL settings. Colleagues who advocate social and political change through the ESL classroom espouse a vision of a better society and a way to attain it. The advocacies and agendas with this outlook are many. Snelbecker (1994) reports varied approaches to dealing with homophobia in professional settings. Cochran (1996), recognizing that female ESL students are often disadvantaged by imposed constraints, cites ways instructors can encourage gender equality. Schenke (1996) views feminism as not just a social issue, but "a way of thinking ... of teaching, and ... of learning" (p. 158). Others have woven a religious agenda into their ESL curriculum for presentation to unsuspecting students in secular institutions. Most probably, regardless of intentionality, the personal values and advocacies of instructors eventually shine through one way or another. Yet determined infusion of these topics and advocacies into instructional material without thoughtful determination of students' interests and institutional expectations raises a number of ethical questions. Might not contentious topical material for some students raise rather than lower what in Krashen's (1985) acquisition model is the hampering affective filter? Do ESL students possess the language facility and self-confidence to articulate their own authentic viewpoint in the face of instructor authority? Will not the instructor's position on a controversial topic invite inauthentic student assent and conformity? Will the ESL or EFL employer endorse or even approve the inclusion of these advocacies in classrooms?

There are other ways an instructor can overlook, dismiss, or even trample valued convictions of an ESL student. Some communicative activities, in an effort to foster negotiation skill, require students to face a hypothetical ethical dilemma. For example, given the description of several characters of varying 
sociological standing and a situation of dwindling lifesaving resources, students are asked to choose and justify the characters to be spared and those to be left to perish in the unfolding situation. This exercise, however, assumes the students can conscientiously assume the role of one who pronounces virtual death sentences. For students who hold to the sanctity of every life, the very thought of consenting to the death of others is repugnant Similarly, the controversial topics of abortion, euthanasia, terrorism, and war all run the risk of offending students and diverting attention from the basic aims of an ESL course.

Instructors must recognize the possibility of offensive clashes in values and be prepared to retreat as necessary in the interests of student learning. Speck's (1996) inquiry into the experience of 70 Muslim students in a United States university at large exposed the presence of such conflict in university classrooms. Reportedly, $37 \%$ of the respondents claimed they had encountered course content that conflicted with their own religious beliefs, and $26 \%$ indicated that course content had at some time been offensive to them. Inevitably, the content of some academic courses will entail theories or notions that unavoidably clash with beliefs of some students. Although there is less likelihood of this kind of conflict in ESL courses, my own student's reaction to the representation of the Palestinian-Israeli incident is a reminder that conflicts and offense do arise. When careful planning and judicious replies to classroom questions still bring offense to students, the ESL instructor must be alert to detect this development and make amends with individuals as needed.

This fifth guideline for ethical discernment in determining lesson content at this point concerns what to omit or circumvent rather than what to include in deference to the principle of nonmaleficence. Gareis (1997), thinking of cross-cultural conflict in language courses, offers practical pointers for dealing with students' sensitivities when reading modern literature or viewing contemporary films. She advises careful previewing of material, analysis of students' backgrounds, class-wide consultation on prospective materials, and planning alternative assignments for objectors. She suggests, apparently for objectors at more advanced levels, a research task on the production and rating of the film. Or individuals can be guided into the study of linguistic register and cultural norms in reference to unacceptable language or offensive scenes in films or literature.

\section{Summary and Conclusion}

I urge ESL teachers and program administrators to keep in view five guidelines for assessing the topical content of the materials they select for use in ESL lessons. The five guidelines rest on one well-established model for ethical judgment in the implementation of many kinds of social services. Here the principles of the model are applied to the ethical treatment of ESL 
learners for the best possible adjustment to their new circumstances. In summary, instructors should introduce topics that maximize students' capacity to function in their new surroundings, develop in them appreciation for new language-learning activites, and connect with students' various interests in learning. Furthermore, selections must inculcate in learners the notions and practice of school standards and respect for others who hold contrasting views grounded in traditions other than their own.

The topics ESL instructors bring to their classrooms have great potential for good or ill. Well chosen topics, be they embedded in written texts or oral presentation, seize learners' attention, ensure meaningful interaction, and sustain students' motivation to learn. Topics can also give orientation to learners as they cope with strange surroundings, unfamiliar classroom pedagogy, and new expectations in their school or university setting. On the other hand, poor or indifferent topic selection can weigh heavily on students and even alienate them from classmates, instructors, the second language itself, and the entire learning community.

An ancient Biblical proverb is timely: "Do not withhold good from those who deserve it, when it is in your power to act" (Prov. 3:27, New International Version). As the communicative approach endows instructors with the power to choose and use topics and texts, there is a new capacity for doing good in the ESL classroom. When instructors grasp the ethical import of the topics they select and integrate into their lesson material, much good can be delivered to their students. Toward that end, these guidelines offer assistance in a critical area of curricular decision that can ultimately contribute to students' well-being in their present endeavors and beyond.

Undoubtedly, there are further issues to consider in ethical determination of ESL lesson topics, issues residing in the outlook of both learners and instructors. Much can be learned through surveys of groups of learners about aspects of culture shock, ways of learning, topics of interest, roles of students, and attitudes toward ideological challenge. Speck's (1996) inquiry into the sensitivities of Muslim students can be extended to discover the impressions of learners of other socio-religious backgrounds. In the TESOL profession itself the views of instructors who represent other than the Judaic-Christian heritage must be considered. Any emerging fuller statement on ethical issues in ESL material content is certain to benefit teachers, material writers and publishers, and the thousands of language-learners served by the profession.

Discreet choice of topics does more than ensure that students learn maximally useful language, acquire beneficial academic habits, and gain essential orientation to their school, college, or university. That is, benefits accrue to the host institution as well. As instructors are mindful of ethical principles in selecting course topical content, students are more apt to view positively their educational experience, the host society at large, and perhaps subconsciously the ESL teaching profession as well. This student outlook, when 
widely shared, is sure to influence newly arriving less proficient students in their expectations of ESL programs. The programs that deliver what incoming students need out of ethical concern for them are sure to hold the edge over those that may remain inattentive to this need.

\section{The Author}

Glenn Deckert, an associate professor of ESL/TESOL, has taught ESL and MATESOL courses at Eastern Michigan University since 1993. Previously, he held EFL positions in Iran, Saudi Arabia, and Hong Kong and fulfilled shorter assignments in Central Asia and Qatar. His research interests are ESL methodology and cultural influences on learning.

\section{References}

Brown, H.D. (2002). Strategies for success: A practical guide to learning English. White Plains, NY: Longman.

Cochran, E.P. (1996). Gender and the ESL classroom. TESOL Quarterly, 30, 159-162.

Cortazzi, M., \& Jin, L. (1999). Cultural mirrors: Materials and methods in the EFL classroom. In E. Hinkel (Ed.), Culture in second language teaching and learning (pp. 196-219). Cambridge, UK: Cambridge University Press.

Duff, P.A. (2001). Language, literacy, content, and (pop) culture: Challenges for ESL students in mainstream courses. Canadian Modern Language Review, 58(1), 103-132.

Duff, P.A. (2002). Pop culture and ESL students: Intertextuality, identity, and participation in classroom discussion. Journal of Adolescent and Adult Literacy, 46(6), 482-487.

Dunkel, P. (1995). Authentic second/foreign language listening texts: Issues of definition, operationalization, and application. In P. Byrd (Ed.), Material writer's guide (pp. 95-106). New York: Heinle \& Heinle.

Freire, P. (1970). Pedagogy of the oppressed. (M.B. Ramos, Trans.). New York: Seabury.

Gareis, E. (1997). Movies in the language classroom: Dealing with problematic content. TESOL Journal, 6(4), 20-23.

Heiman, J.D. (1994). Western culture in EFL language instruction. TESOL Journal, 3(3), 4-7.

Johnson, B. (2003). Values in English language teaching. Mahwah, NJ: Erlbaum.

Kitchener, K.S. (1984). Intuition, critical evaluation and ethical principles: The foundation for ethical decisions in counseling psychology. Counseling Psychologist, 12(3), 43-56.

Kitchener, K.S. (2000). Foundations of ethical practice, research, and teaching in psychology. Mahwah, NJ: Erlbaum.

Krashen, S.D. (1985). The input hypothesis: Issues and implications. New York: Longman.

Messerschmitt, D., Hafernik, J.J., \& Vandrick, S. (1997). Culture, ethics, scripts, and gifts. TESOL Journal, 7(2), 11-14.

Morrison, T., Conaway, W.A., \& Borden, G. (1994). Kiss, bow or shake hands: How to do business in 60 countries. Holbrook, MA: Bob Adams.

Nunan, D. (1988). The learner-centred curriculum. Cambridge, UK: Cambridge University Press.

Pennycook, A. (1994). The cultural politics of English as an international language. London: Longman.

Russy, C. de. (2003, September 19). Professional ethics begin on the college campus. Chronicle of Higher Education, p. B20.

Schenke, A. (1996). Feminist theory and the ESL classroom. TESOL Quarterly, 30, 155-159.

Schmidt, S. (2004, March 31). Profs axe take-home papers: "It's a pity": End-of-term essay on chopping block in plagiarism fight. National Post, p. A20. Retrieved June 30, 2004, from LexisNexis Academic Database.

Silva, T. (1997). On the ethical treatment of ESL writers. TESOL Quarterly, 31(2), 359-363.

Sir Wilfrid Laurier Secondary School. (n.d.). Avoiding plagiarism. Retrieved June 30, 2004, from http://www.swil.ocdsb.edu.on.ca/ swl_library/plagiarism.html 
Snelbecker, K.A. (1994). Speaking out: A survey of lesbian, gay, and bisexual teachers of ESOL in the U.S. Unpublished master's thesis, School for International Training, Brattleboro, VT. (ERIC Document Reproduction Service No. ED 375680 )

Speck, B.W. (1996). Professor bias, religion, and ESL students: The need for a reflective pedagogy. College Student Journal, 30(3), 390-399.

The Holy Bible, New International Version. (1978). London: Hodder and Stoughton.

Varadi, M. (2004, January 22). A whole new lingo. Toronto Star, p. P03. Retrieved June 30, 2004, from LexisNexis Academic Database.

Watson, D.I. (1999). "Loss of face" in Australian classrooms. Teaching in Higher Education, 4(3), 355-362.

Welfel, E.R. (1990). Ethical practice in college student affairs. In D.G. Creamer \& Associates (Eds.), College student development: Theory and practice for the 1990's (pp. 195-216). Alexandria, VA: American College Personnel Association. 